\title{
Cardiotrophin-Like Cytokine/Cytokine-Like Factor 1 is an Essential Trophic Factor for Lumbar and Facial Motoneurons In Vivo
}

\author{
Nancy G. Forger, ${ }^{1}$ David Prevette, ${ }^{2}$ Odile deLapeyrière, ${ }^{3}$ Béatrice de Bovis, ${ }^{3}$ Siwei Wang, ${ }^{2}$ Perry Bartlett,,${ }^{4}$ and \\ Ronald W. Oppenheim ${ }^{2}$ \\ ${ }^{1}$ Department of Psychology and Center for Neuroendocrine Studies, University of Massachusetts, Amherst, Massachusetts 01003, ${ }^{2}$ Department of \\ Neurobiology and Anatomy, Wake Forest University School of Medicine, Winston-Salem, North Carolina 27157, ${ }^{3}$ Institut National de la Santé et de la \\ Recherche Médicale (INSERM) U.382, Developmental Biology Institute of Marseille, Centre National de la Recherche Scientifique-INSERM-Universite de \\ la Mediterranee, 13288 Marseille Cedex 09, France, and ${ }^{4}$ School of Biomedical Sciences, University of Queensland, Brisbane 4067 Australia
}

The ciliary neurotrophic factor $\alpha$-receptor (CNTFR $\alpha$ ) is required for motoneuron survival during development, but the relevant ligand(s) has not been determined. One candidate is the heterodimer formed by cardiotrophin-like cytokine (CLC) and cytokine-like factor 1 (CLF). CLC/CLF binds to CNTFR $\alpha$ and enhances the survival of developing motoneurons in vitro; whether this novel trophic factor plays a role in neural development in vivo has not been tested. We examined motor and sensory neurons in embryonic chicks treated with CLC and in mice with a targeted deletion of the $c l f$ gene. Treatment with CLC increased the number of lumbar spinal cord motoneurons that survived the cell death period in chicks. However, this effect was regionally specific, because brachial and thoracic motoneurons were unaffected. Similarly, newborn $c l f-/-$ mice exhibited a significant reduction in lumbar motoneurons, with no change in the brachial or thoracic cord. $C l f$ deletion also affected brainstem motor nuclei in a regionally specific manner; the number of motoneurons in the facial but not hypoglossal nucleus was significantly reduced. Sensory neurons of the dorsal root ganglia were not affected by either CLC treatment or $c l f$ gene deletion. Finally, mRNA for both $c l c$ and $c l f$ was found in skeletal muscle fibers of embryonic mice during the motoneuron cell death period. These findings support the view that CLC/CLF is a target-derived factor required for the survival of specific pools of motoneurons. The in vivo actions of CLC and CLF can account for many of the effects of CNTFR $\alpha$ on developing motoneurons.

Key words: motoneuron; cell death; trophic factor; cardiotrophin; cytokine; ciliary neurotrophic factor

\section{Introduction}

The ciliary neurotrophic factor (CNTF) receptor, which consists of a specific ligand-binding subunit, ciliary neurotrophic factor $\alpha$-receptor $(\operatorname{CNTFR} \alpha)$, and two signal transducing subunits, gp130 and leukemia inhibitory factor receptor $\beta(\operatorname{LIFR} \beta)$, is required for development of the normal complement of spinal and cranial motoneurons. Mice lacking any of the three receptor components die perinatally and exhibit significant reductions in motoneuron number (DeChiara et al., 1995; Li et al., 1995; Nakashima et al., 1999). However, the ligand acting through CNTFR $\alpha$ to control motoneuron number is not known. CNTF itself is not a secreted protein and is not expressed at appreciable levels during the cell death period (Stöckli et al., 1989). Moreover, in contrast to the effects of CNTFR $\alpha$ gene deletion, a deletion of the CNTF gene does not affect motoneuron number during de-

Received June 5, 2003; revised August 1, 2003; accepted August 4, 2003.

This work was supported by grants from the National Institutes of Health (N.G.F. and R.W.O.), Institut National de la Santé et de la Recherche Médicale, Centre National de la Recherche Scientifique, and the Association Française contre les Myopathies (0.D.).We gratefully acknowledge J.-F. Gauchat for providing $c k$ and $c / f$ probes and Warren Alexander for providing If mutant mice.

Correspondence should be addressed to Nancy G. Forger, Department of Psychology, University of Massachusetts, Amherst, MA 01003. E-mail: nforger@psych.umass.edu.

Copyright $\odot 2003$ Society for Neuroscience $\quad$ 0270-6474/03/238854-05\$15.00/0 velopment (Masu et al., 1993). This has led to the proposition that CNTFR $\alpha$ must serve as a receptor for another developmentally important ligand.

Recently, a heterodimer of cytokine-like factor 1 (CLF) and cardiotrophin-like cytokine (CLC) was proposed to be the CNTFR $\alpha$ ligand controlling the survival of developing motoneurons (Elson et al., 2000). CLF (also known as NR6) is a soluble receptor with significant homology to cytokine type I receptors (Elson et al., 1998; Alexander et al., 1999). CLC [also known as novel neurotophin-1/B cell-stimulating factor-3 (NNT-1/BSF3 )] is a cytokine of the interleukin- 6 family with high homology to CNTF and cardiotrophin-1 (CT-1) (Senaldi et al., 1999; Shi et al., 1999). When supplied exogenously, CLC activates the CNTF receptor and supports the survival of embryonic chick motoneurons in culture (Senaldi et al., 1999). Although CLC contains a putative signaling peptide characteristic of secreted proteins, it is not secreted when expressed alone (Elson et al., 2000). However, coexpression of CLC with CLF results in a stable complex (CLC/ CLF), which is efficiently secreted and acts only on cells expressing functional membrane-bound CNTF receptors (Elson et al., 2000; Lelièvre et al., 2001). Mice with a targeted deletion of the clf gene exhibit a phenotype similar to CNTFR $\alpha$ knock-out mice, in that they fail to suckle and die soon after birth (Alexander et al., 
1999). Although the brains of $c l f-/-$ mice are grossly normal (Alexander et al., 1999), their neural phenotype has not been examined in any detail. Therefore, it is not known whether deletion of $c l f$ results in the same neural deficits seen in CNTFR $\alpha$ mutants. We tested the roles of CLC and CLF by examining the effects of CLC on neuronal survival in embryonic chicks in vitro and in vivo, by assessing the effects of $c$ lf gene deletion on motor and sensory neuron number in newborn mice, and by examining expression patterns of $c l c$ and $c l f$ in embryonic skeletal muscle.

\section{Materials and Methods}

Chick motoneuron cultures. Lumbar spinal cords were dissected from embryonic day (E) 5 (stage 26) chick embryos, and purified motoneurons were cultured for $48 \mathrm{hr}$ in serum-free medium as described previously (Milligan et al., 1994). Hindlimb muscles from E16 (stage 42) embryos were used to prepare muscle extracts (MEXs) as described previously (Oppenheim et al., 1988). Chick embryo MEX or neurotrophic factors were added at the following doses, which were shown previously to optimally support motoneuron survival (Oppenheim et al., 1988; Milligan et al., 1994; Senaldi et al., 1999): $100 \mathrm{ng} / \mathrm{ml} \mathrm{CT-1,} 100 \mathrm{ng} / \mathrm{ml} \mathrm{CLC}$ (generously provided by Giorgio Senaldi, Amgen, Thousand Oaks, CA), and $10 \mathrm{ng} / \mathrm{ml}$ CNTF. Motoneuron survival after $48 \mathrm{hr}$ was expressed relative to survival in the presence of MEX (Oppenheim et al., 1995).

In ovo treatment with CLC. CLC (5 $\mu$ g in PBS) or PBS alone was applied daily through a small window in the shell onto the vascularized chorio-allantoic membrane of developing chick embryos. Embryos were treated from E5-E9 and killed on E10. Spinal cords were fixed in Carnoy's solution, embedded in paraffin, sectioned at $10 \mu \mathrm{m}$, and stained with thionin. Counts were made as described below of lumbar, brachial, and thoracic motoneurons, as well as of dorsal root ganglion (DRG) sensory neurons at the third lumbar segment.

Clfknock-out mice. Mice heterozygous for a targeted deletion of the clf gene were generously provided by Dr. Warren Alexander (Walter and Eliza Hall Institute, Melbourne, Australia). Offspring of heterozygous matings were collected on the day of birth and genotyped by Southern blotting of tail DNA (Alexander et al., 1999). Brains and spinal cords were fixed in Bouin's solution, embedded in paraffin, sectioned at $10 \mu \mathrm{m}$, and stained with cresyl violet. Counts were made of motoneurons in the brachial [corresponding approximately to cervical segment (C) 1 and $\mathrm{C} 2]$, thoracic, and lumbar levels of the spinal cord, as well as in the facial and hypoglossal nuclei of the brainstem. The number of DRG sensory neurons was determined at C6. All cell counts were performed blind to the treatment condition. Motoneurons and DRG sensory neurons were counted in every fifth section through each population, and sums were multiplied by five to estimate total cell numbers. Only cells with a large Nissl-positive soma, in which the nucleus and nucleolus were clearly visible, were counted using criteria that effectively eliminated the possibility of counting the same cell twice (Clarke and Oppenheim, 1995).

In situ hybridization for clc and clf. Mouse embryos (E14.5-E18.5) were fixed with $4 \%$ paraformaldehyde, cryopreserved in $15 \%$ sucrose, and cut transversely at $16 \mu \mathrm{m}$. In situ hybridization was performed as described previously (Garcès et al., 2001), with digoxigenin (DIG)labeled $c l c$ and $c l f$ riboprobes kindly provided by J. F. Gauchat (University of Montreal, Montreal, Canada). To confirm that muscle fibers, per se, express $c l c$ and $c l f$, double in situ hybridization-immunohistochemistry was performed as described previously (Carroll et al., 2001) on sections from E16.5 myosin-light chain (MLC) nlacZ mice, which express the nlac $Z$ reporter gene under the control of a muscle-specific myosin-light chain promoter (Kelly et al., 1997). After in situ hybridization, slides were rinsed, exposed to a blocking solution, and incubated overnight at $4^{\circ} \mathrm{C}$ with rabbit anti- $\beta$-Gal. After washes, slides were incubated with biotinylated donkey anti-mouse secondary antibody, washed, and incubated in $\mathrm{ABC}$ streptavidin-HRP. Staining was revealed with $\mathrm{DAB}$ in the presence of $\mathrm{H}_{2} \mathrm{O}_{2}$.

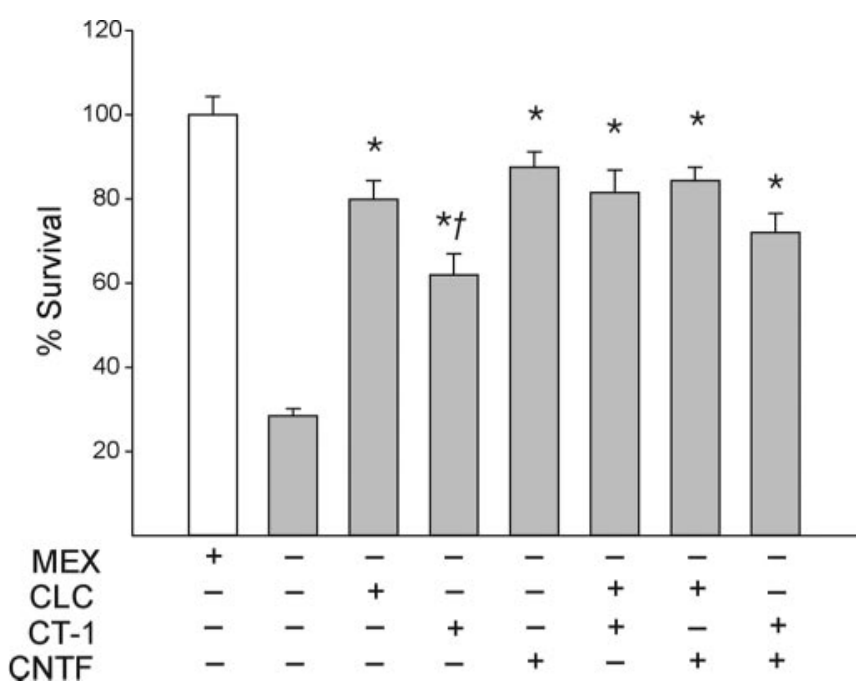

Figure 1. Effect of $\mathrm{CLC}, \mathrm{CT}-1$, and CNTF alone and in combination on the survival of embryonic chick motoneurons in culture. Data are expressed as a percentage of survival (mean \pm SEM) relative to chick embryo MEX. Data from four independent replications were analyzed by ANOVA followed by planned comparisons. ${ }^{*}$, Significantly different from control condition; $\dagger$, significantly different from CLC alone.

\section{Results \\ Effects of CLC, CT-1, and CNTF on motoneuron survival in embryonic chicks in vitro}

Between E5 and E9, approximately one-half of the motoneurons present in the chick lumbar spinal cord die by programmed cell death (Hamburger, 1975). CLC, CT-1, and CNTF share common receptor subunits, and each have been reported to protect embryonic chick motoneurons from cell death in vitro (Arakawa et al., 1990; Senaldi et al., 1999; Oppenheim et al., 2001). We directly compared the effects of CLC with those of CT-1 and CNTF and asked whether sparing of motoneurons was increased by combining trophic factors. Survival was expressed relative to the protection provided by chick embryo MEX. Lumbar motoneurons collected from E5 chicks either received no treatment (control) or were exposed for $48 \mathrm{hr}$ to MEX, CT-1, CLC, CNTF, or combinations of the trophic factors. CT-1, CLC, and CNTF each enhanced motoneuron survival relative to the control condition when presented alone $(p<0.0005)$ (Fig. 1). CLC was as potent a survival factor as CNTF at the doses tested $(\sim 80$ and $87 \%$ sparing, respectively; $p>0.05)$ and was somewhat more effective than CT-1 in this regard $(p<0.01)$. The combination of CLC plus CNTF or CLC plus CT-1 did not further enhance survival over that of CLC alone $(p>0.05)$. This confirms that CLC is a potent survival factor for embryonic chick motoneurons in vitro, and the effects of CLC are not additive with CNTF or CT-1.

\section{Effect of CLC on neuron survival in ovo}

To examine whether CLC could enhance motoneuron survival during the developmental cell death period in vivo, $5 \mu \mathrm{g}$ of CLC was administered to embryonic chicks from E5-E9. Embryos were killed on E10, and counts were made of motoneurons in the lumbar, brachial, and thoracic spinal cord. CLC resulted in a significant $35 \%$ increase in the number of lumbar motoneurons surviving the cell death period (Table 1$)(p<0.002)$. However, CLC had no effect on brachial or thoracic motoneuron number $(p>0.20$ and $p>0.35$, respectively). In contrast to the involvement of the CNTF receptor in motoneuron development, sensory neurons of the DRG were not affected by the deletion of 
Table 1. Neuron number (mean \pm SEM) on E10 in chicks treated with PBS or CLC from $E 5$ to $E 9$

\begin{tabular}{lccl}
\hline & Control (PBS) & CLC & Percentage of control \\
\hline Brachial $(n=6)$ & $9080 \pm 594$ & $8350 \pm 369$ & $92 \mathrm{~ns}$ \\
Thoracic $(n=3)$ & $1180 \pm 59$ & $1210 \pm 52$ & $103 \mathrm{~ns}$ \\
Lumbar $(n=6)$ & $11704 \pm 284$ & $15783 \pm 404$ & $135,{ }^{*} p<0.002$ \\
L3 DRG $(n=3)$ & $10346 \pm 197$ & $10562 \pm 143$ & $102 \mathrm{~ns}$ \\
\hline
\end{tabular}

$\mathrm{ns}$, No significant difference between groups; $n$, number of animals in each group.

\begin{tabular}{|c|c|c|c|}
\hline & $d f+/+$ & df $-/-$ & Percentage of control \\
\hline \multicolumn{4}{|l|}{ Spinal cord } \\
\hline Brachial $(n=6)$ & $2672 \pm 160$ & $2420 \pm 182$ & $91 \mathrm{~ns}$ \\
\hline Thoracic $(n=3)$ & $1870 \pm 163$ & $1735 \pm 107$ & $93 \mathrm{~ns}$ \\
\hline Lumbar $(n=8)$ & $2741 \pm 147$ & $2018 \pm 140$ & $74,{ }^{*} p<0.012$ \\
\hline C6DRG $(n=3)$ & $5642 \pm 281$ & $5452 \pm 394$ & $97 \mathrm{~ns}$ \\
\hline \multicolumn{4}{|l|}{ Brainstem } \\
\hline Facial $(n=5)$ & $3953 \pm 127$ & $2841 \pm 280$ & $72,{ }^{*} p<0.01$ \\
\hline Hypoglossal $(n=5,3)$ & $1158 \pm 160$ & $1060 \pm 039$ & $92 \mathrm{~ns}$ \\
\hline
\end{tabular}

ns, No significant difference between groups; $n$, number of animals in each of the two groups except for hypoglossal, in which five $\mathrm{dlf}+/+$ and three $\mathrm{df}-/-$ brains were examined.

CNTFR $\alpha$ (DeChiara et al., 1995). Similarly, counts of DRG neurons at lumbar segment 3 indicated that the survival of sensory neurons was not affected by CLC administration in embryonic chicks $(p>0.20)$ (Table 1$)$.

\section{Effects of clf gene deletion in newborn mice}

Although CLC can rescue motoneurons when provided exogenously, CLC is not secreted from cells unless coexpressed with the soluble receptor CLF (Elson et al., 2000). Thus, if CLC/CLF is an essential trophic factor acting through CNTFR $\alpha$ to spare developing motoneurons, then deletion of CLF should reduce motoneuron survival. To test this, we compared motoneuron number in $c l f+/+$ and $c l f-/-$ mice. Clf gene deletion reduced the total number of lumbar motoneurons in newborn mice by $26 \%$ (Table 2) $(p<0.012)$. Preliminary analysis suggests that a single copy of the $c l f$ gene may suffice to maintain normal motoneuron number, because counts in the lateral horn of the lower lumbar spinal cord (L5-L6) of $c l f+/-$ mice $(357 \pm 6)$ are greater than those in knock-out mice $(270 \pm 12 ; p<0.001)$ and equivalent to those in wild-type animals ( $362 \pm 13 ; p>0.70$ vs $c l f+/-)$.

The effect of $c l f$ gene deletion on spinal motoneuron number was specific to the lumbar spinal cord, because there was no difference in the number of brachial or thoracic motoneurons between $c l f+/+$ and $c l f-/-$ mice (Table 2 ). Regionally specific effects were also found for brainstem motoneurons: $c l f$ deletion significantly decreased the number of facial motoneurons $(p<$ 0.01 ) but did not affect the number of hypoglossal motoneurons. The absence of $c l f$ also did not affect the number of sensory neurons in the mouse DRG (Table 2).

\section{Expression of $c l c$ and $c l f$ in embryonic mice}

If the CLC/CLF complex is a target-derived trophic factor for motoneurons, then one would expect expression of CLC and CLF in developing striated muscle. Previously, clfmRNA was reported in limb buds of E11.5 mouse embryos (Alexander et al., 1999), but expression specifically within developing muscle has not been examined. Motoneuron loss in mice lacking gp130, a signaling component of the CNTF receptor, occurs between E14.5 and E18.5 (Nakashima et al., 1999). By in situ hybridization, we found that both $c l c$ and $c l f$ mRNAs are expressed in muscle tissue of embryonic mice on E16.5 (Fig. 2). Although staining intensity varies from muscle to muscle, signal is detected in muscles throughout the embryo, including in the forelimbs, trunk, hindlimbs, and the head and neck region. A similar pattern of expression of $c l c$ and $c l f$ was observed on E14.5 and E18.5 (data not shown). To confirm the identity of the positive cells, we used transgenic mice with the nlac $Z$ reporter gene under the control of the muscle-specific MLC promoter (Kelly et al., 1997). Combined in situ hybridization and immunohistochemistry confirmed that many $\mathrm{clc}^{+}$and $\mathrm{clf}^{+}$cells are in fact muscle fibers (Fig. 2). Thus, $c l c$ and $c l f$ are both expressed in skeletal muscles during the motoneuron cell death period.

\section{Discussion}

CLC attenuated motoneuron cell death in embryonic chicks in vitro and in vivo. In addition, clf gene deletion reduced the number of motoneurons in the lumbar spinal cord and facial nucleus of newborn mice, indicating that expression of this soluble receptor is required for development of the normal complement of spinal and cranial motoneurons. Because biological activity of CLF has been demonstrated only when bound to CLC (Elson et al., 2000; Lelièvre et al., 2001), it is likely that the motoneuron loss in clf knock-out mice is attributable to loss of the secreted CLC/ CLF heteromer. Finally, we observed expression of both $\mathrm{clc}$ and $\mathrm{clf}$ in muscle fibers of embryonic mice. Together, these findings suggest that CLC/CLF is a target-derived trophic factor selectively required for the survival of motoneurons, including lumbar and facial motoneurons, during the developmental cell death period.

A large number of trophic factors that enhance motoneuron survival when supplied exogenously have been identified (for review, see Oppenheim, 1996; Kilpatrick and Soilu-Hänninen, 1999). Nonetheless, it is somewhat unusual for the disruption of a single growth or trophic factor gene to affect motoneuron number (Elliott and Snider, 1996), presumably because redundancy in trophic factor supply is able to compensate for the loss of most individual factors. CLC/CLF now joins glial cell line-derived neurotrophic factor (GDNF) and cardiotrophin-1 as factors essential for the normal development of motoneuron number (Moore et al., 1996; Oppenheim et al., 2001). However, the requirement for CLC/CLF appears to be regionally specific. Clf gene deletion in mice did not affect cell number in the rostral spinal cord or in the hypoglossal nucleus; similarly, brachial and cervical motoneurons were not rescued by CLC administration in chicks. These observations add to a growing body of evidence suggesting that subpopulations of motoneurons differ in their trophic requirements.

For example, GDNF is required for the survival of distinct subpopulations of motoneurons, which can be defined by their pattern of receptor expression and location in the spinal cord (Garcès et al., 2000; Oppenheim et al., 2000). Similarly, hepatocyte growth factor is a more potent survival factor for limb than for nonlimb motoneurons (Yamamoto et al., 1997; Novak et al., 2000), a difference that may be attributed to differential expression of the c-met receptor. Expression of the fibroblast growth factor receptor is also restricted to specific motor pools (Philippe et al., 1998). Such regional specificity in receptor expression could result from differential expression of homeodomain transcription factors within motoneuron subclasses during early development (Pfaff and Kintner, 1998) and from influences of peripheral targets or afferent inputs. This raises the question of whether there is differential expression of the receptors for CLC/ CLF at different spinal and cranial sites. We noted that the CNTF $\alpha$-receptor is expressed in subsets of lumbar motor pools that 


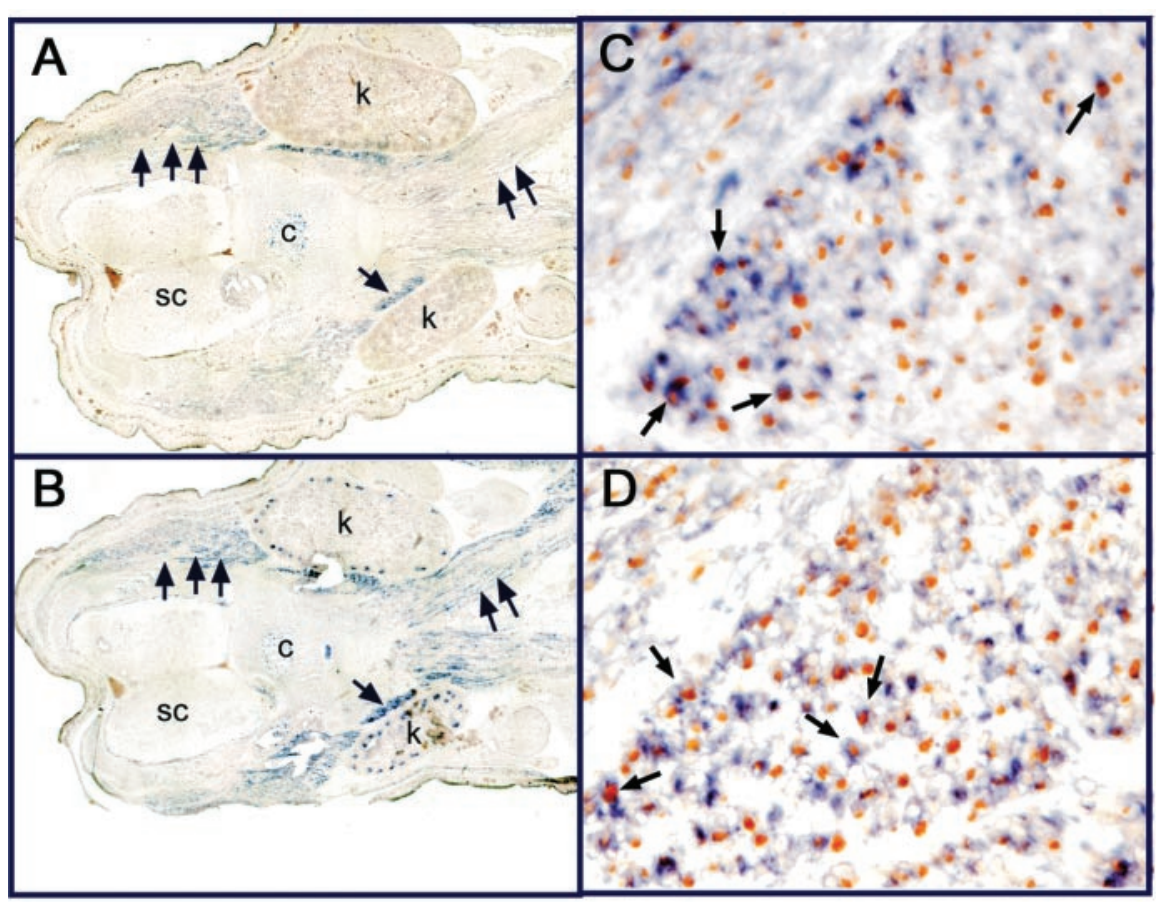

Figure 2. Detection of $c l c(A)$ and $c l f(B)$ mRNAs (blue staining) in transverse sections of E16.5 mouse embryos at the lumbar level by in situ hybridization. Muscle tissue is positive for both probes (arrows). Also note clf expression in the kidney as described by Alexander et al. (1999). The identity of the clc- or clf-positive cells as muscle fibers was confirmed by double staining. In situ hybridization using DIG-labeled probes for $c k(C)$ and $c I f(D)$ was performed on sections of thigh muscles from E16.5 MLCnlacZ mice, which express the nlacZ reporter gene under the control of a muscle-specific MLC promoter. Subsequently, the sections were processed for immunohistochemical detection of $\beta$-Gal. Strongly clc- or clf-positive cells (blue cytoplasmic staining) are also $\beta$-Gal positive (brown nuclear staining). Arrows indicate double-labeled cells. sc, Spinal cord; k, kidney; c, cartilage.

knock-out mice. We observed a $28 \%$ reduction in the number of facial nucleus motoneurons, which is slightly lower than the reduction reported in the facial nucleus of CNTFR $\alpha$, LIFR $\beta$, or gp130 mutants (losses of 33-41\%). Similarly, $\operatorname{CNTFR} \alpha, \operatorname{LIFR} \beta$, and gp 130 mutants display a reduction in lumbar motoneurons of $\sim 30-40 \%$ (DeChiara et al., 1995; Li et al., 1995; Nakashima et al., 1999), compared with a $26 \%$ reduction in the lumbar motor column seen in CLF mutants. Given the regional specificity of CLC action and clf deletion observed here, it would be of interest to know whether motoneurons in the thoracic or brachial spinal cord are affected in mice lacking CNTFR $\alpha$, LIFR $\beta$, or gp130. However, as far as we are aware, spinal motoneurons outside the lumbar motor column have not been examined in any of the three receptor mutants.

There is at least one effect of CNTFR $\alpha$ deletion that does not seem to be explained by the loss of CLC/CLF signaling. We did not observe a significant effect of clf gene deletion on hypoglossal motoneurons, in contrast to a $>50 \%$ reduction reported in the hypoglossal nucleus of CNTFR $\alpha-/-$ mice (DeChiara et al., 1995). It has been reported recently that coexpression of CLC and CNTFR $\alpha$ in

innervate specific leg muscles in the chick embryo (T. Gould and R. Oppenheim, unpublished observations). However, we are not aware of reports demonstrating differences among motoneuron groups in the expression of CNTF receptor components that would explain the pattern of results observed here. CNTFR $\alpha$ appears to be expressed by most motoneurons in rodents (MacLennan et al., 1996; Lee et al., 1997; Forger et al., 1998), but receptor expression has not been analyzed quantitatively, and the challenging triple labeling which would be required to identify all three receptor subunits required for CNTF or CLC/CLF signaling within individual motor pools has not been performed.

Differential expression of CLC and CLF by target muscles could also account for regional differences in the effect of $c$ lf gene deletion. However, that explanation seems unlikely here. $\mathrm{Clc}$ and clf mRNAs were found not only in hindlimb muscles (i.e., the targets of lumbar motoneurons) but also in muscles innervated by motoneurons not affected by clf gene deletion (e.g., trunk muscles and tongue). In addition, administration of CLC to embryonic chicks rescued lumbar but not brachial or thoracic motoneurons, arguing against the idea that regional specificity is attributable to availability of the trophic factor and suggesting instead regional variability in responsiveness or intracellular signaling.

The CLC/CLF heteromer has been proposed as the developmentally relevant ligand acting through the CNTF receptor (Elson et al., 2000). Loss of any of the three CNTF receptor subunits, CNTFR $\alpha, \operatorname{LIFR} \beta$, or gp130, results in a significant reduction in spinal and cranial motoneurons (DeChiara et al., 1995; Li et al., 1995; Nakashima et al., 1999), and a comparison of the effects of clfgene deletion with previous reports suggests that CLC/CLF can account for much of the motoneuron loss seen in the receptor mammalian cells in vitro generates a secreted cytokine (CLC/ CNTFR $\alpha$ ) displaying activities on cells expressing the receptors gp130 and LIFR $\beta$ (Plun-Favreau et al., 2001). If this also occurs in vivo, the absence of secreted CLC/CNTFR $\alpha$ complexes may account for effects seen in CNTFR $\alpha$ knock-out mice but not clf knock-out mice. This could be tested in the future by examining the effects of $c l c$ gene deletion on cranial and spinal motoneurons. In summary, our findings support the proposal by Elson et al. (2000) that CLC/CLF is an important, endogenous CNTFR $\alpha$ ligand required for normal neural development, but we do not rule out the possibility that there may be additional, as yet unknown, factors that also signal through the CNTF receptor.

\section{References}

Alexander WS, Rakar S, Robb L, Farley A, Willson TA, Zhang J-G, Hartley L, Kikuchi Y, Kojima T, Nomura H, Hasegawa M, Maeda M, Fabri L, Jachno K, Nash A, Metcalf D, Nicola NA, Hilton D (1999) Suckling defect in mice lacking the soluble haemopoietin receptor NR6. Curr Biol 9:605-608.

Arakawa Y, Sendtner M, Thoenen H (1990) Survival effect of ciliary neurotrophic factor (CNTF) on chick embryonic motor neurons in culture: comparison with other neurotrophic factors and cytokines. J Neurosci 10:3507-3515.

Carroll P, Gayet O, Feuillet C, Kallenbach S, de Bovis B, Dudley K, Alonso S (2001) Juxtaposition of CNR protocadherins and reelin expression in the developing spinal cord. Mol Cell Neurosci 17:611-623.

Clarke PG, Oppenheim RW (1995) Neuron death in vertebrate development: in vitro methods. Methods Cell Biol 46:277-321.

DeChiara TM, Vesjada R, Poueymirou WT, Acheson A, Suri C, Conover JC, Friedman B, McClain J, Pan L, Stahl N, Ip N, Kato A, Yancopoulos GD (1995) Mice lacking the CNTF receptor, unlike mice lacking CNTF, exhibit profound motor neuron deficits at birth. Cell 83:313-322.

Elliott JL, Snider WD (1996) Motor neuron growth factors. Neurology 47 [Suppl 2]:S47-S53. 
Elson GCA, Graber P, Losberger C, Herren S, Gretener D, Menoud LN, Wells TNC, Kosco-Vilbois MH, Gauchat J-F (1998) Cytokine-like factor-1, a novel soluble protein, shares homology with members of the cytokine type I receptor family. J Immunol 161:1371-1379.

Elson GCA, Lelièvre E, Guillet C, Chevalier S, Plun-Favreau H, Froger J, Suard I, Benoit de Ciognac A, Delneste Y, Bonnefoy J-Y, Gauchat J-F, Gascan H (2000) CLF associates with CLC to form a functional heteromeric ligand for the CNTF receptor complex. Nat Neurosci 3:867-872.

Forger NG, Wagner CK, Contois M, Bengston L, MacLennan AJ (1998) Ciliary neurotrophic factor receptor $\alpha$ in spinal motoneurons is regulated by gonadal hormones. J Neurosci 18:8720-8729.

Garcès A, Haase G, Airaksinen MS, Livet J, Filippi P, deLapeyrière O (2000) GFRalpha 1 is required for development of distinct subpopulations of motoneuron. J Neurosci 20:4992-5000.

Garcès A, Livet J, Grillet N, Henderson CE, deLapeyrière O (2001) Responsiveness to neurturin of subpopulations of embryonic rat spinal motoneuron does not correlate with expression of GFR alpha 1 or GFR alpha 2. Dev Dyn 220:189-197.

Hamburger V (1975) Cell death in the development of the lateral motor column of the chick embryo. J Comp Neurol 160:535-546.

Kelly RG, Zammit PS, Schneider A, Alonso S, Biben C, Buckingham ME (1997) Embryonic and fetal myogenic programs act through separate enhancers at the MLC1F/3F locus. Dev Biol 187:183-199.

Kilpatrick TJ, Soilu-Hänninen M (1999) Molecular mechanisms regulating motor neuron development and degeneration. Mol Neurobiol 19:205-228.

Lee MY, Hofmann H-D, Kirsch M (1997) Expression of ciliary neurotrophic factor receptor- $\alpha$ messenger RNA in neonatal and adult rat brain: an in situ hybridization study. Neuroscience 77:233-246.

Lelièvre E, Plun-Favreau H, Chevalier S, Froger J, Cuillet C, Elson GC, Gauchat JF, Gascan H (2001) Signaling pathways recruited by the cardiotrophin-like cytokine/cytokine-like factor-1 composite cytokine: specific requirement of the membrane-bound form of ciliary neurotrophic factor receptor alpha component. J Biol Chem 276:22476-22484.

Li M, Sendtner M, Smith A (1995) Essential function of LIF receptor in motor neurons. Nature 378:724-727.

MacLennan AJ, Vinson EN, Marks L, McLaurin DL, Pfeifer M, Lee N (1996) Immunohistochemical localization of ciliary neurotrophic factor receptor $\alpha$ expression in the rat nervous system. J Neursci 16:621-630.

Masu Y, Wolf E, Holtmann B, Sendtner M, Brem G, Thoenen H (1993) Disruption of the CNTF gene results in motor neuron degeneration. Nature 365:27-32.

Milligan CE, Oppenheim RW, Schwartz LM (1994) Motoneurons deprived of trophic support in vitro require new gene expression to undergo programmed cell death. J Neurobiol 25:1005-1016.

Moore MW, Klein RD, Farinas I, Sauer H, Arnamini M, Phillips H, Reichardt LF, Ryan AM, Carver-Moore K, Rosenthal A (1996) Renal and neuronal abnormalities in mice lacking GDNF. Nature 382:76-79.

Nakashima K, Wiese S, Yanagisawa M, Arakawa H, Kimura N, Hisatsune T,
Yoshida K, Kishimoto T, Sendtner M, Taga T (1999) Developmental requirement of gp130 signaling in neuronal survival and astrocyte differentiation. J Neurosci 19:5429-5434.

Novak KD, Prevette D, Wang S, Gould T, Oppenheim RW (2000) Hepatocyte growth factor/scatter factor is a neurotrophic survival factor for lumbar but not for other somatic motoneurons in the chick embryo. J Neurosci 20:326-337.

Oppenheim RW (1996) Neurotrophic survival molecules for motoneurons: an embarrassment of riches. Neuron 17:195-197.

Oppenheim RW, Haverkamp LJ, Prevette DM, McManaman JL, Appel SH (1988) Reduction of naturally occurring motoneuron death in vivo by a target-derived neurotrophic factor. Science 240:919-922.

Oppenheim RW, Houenou LJ, Johnson JE, Lin LH, Li L, Lo AC, Newsome AL, Prevette DM, Wang S (1995) Developing motor neurons rescued from programmed and axotomy-induced cell death by GDNF. Nature 373:344-346

Oppenheim RW, Houenou LJ, Parsadanian AS, Prevette D, Snider WD, Shen L (2000) Glial cell line-derived neurotrophic factor and developing mammalian motoneurons: regulation of programmed cell death among motoneurons subtypes. J Neurosci 20:5001-5011.

Oppenheim RW, Wiese S, Prevette D, Armanini M, Wang S, Houenou LJ, Holtmann B, Götz R, Pennica D, Sendtner M (2001) Cardiotrophin-1, a muscle-derived cytokine, is required for the survival of subpopulations of developing motoneurons. J Neurosci 21:1283-1291.

Pfaff S, Kintner C (1998) Neuronal diversivication: development of motor neuron subtypes. Curr Opin Neurobiol 8:27-36.

Philippe JM, Carces A, deLapeyrière O (1998) Fgf-R3 is expressed in a subset of chicken spinal motoneurons. Mech Dev 78:119-123.

Plun-Favreau H, Elson G, Chabbert M, Froger J, deLapeyrière O, Lelièvre E, Cuillet C, Hermann J, Gauchet J-F, Gascan H, Chevalier S (2001) The ciliary neurotrophic factor receptor $\alpha$ component induces the secretion of and is required for functional responses to cardiotrophin-like cytokine. EMBO J 20:1692-1703.

Senaldi G, Varnum BC, Sarmiento U, Starnes C, Lile J, Scully S, Guo J, Elliott G, McNinch J, Shaklee CL, Freeman D, Manu F, Simonet WS, Boone T, Chang M-S (1999) Novel neurotrophin-1/B cell-stimulating factor-3: a cytokine of the IL-6 family. Proc Natl Acad Sci USA 96:11458-11463.

Shi Y, Wang W, Yourey PA, Gohari S, Zukauskas D, Zhang J, Ruben S, Alderson RF (1999) Computational EST database analysis identifies a novel member of the neuropoietic cytokine family. Biochem Biophys Res Commun 262:132-138.

Stöckli K, Lottspeich F, Sendtner M, Masiakowski P, Carroll P, Gotz R, Lindholm D, Thoenen H (1989) Molecular cloning, expression and regional distribution of rat ciliary neurotrophic factor. Nature 342:920-922.

Yamamoto Y, Livet J, Pollock RA, Garcès A, Arce V, deLapeyrière O, Henderson CE (1997) Hepatocyte growth factor (HGF/SF) is a muscle-derived survival factor for a subpopulation of embryonic motoneurons. Development 124:2903-2913. 